\title{
Glycogen-Storage Disease in Rats, A Genetically Determined Deficiency of Liver Phosphorylase Kinase
}

\author{
Rex MALTHUS, Dallas G. CLARK, ${ }^{*}$ Colin WATTS and John G. T. SNEYD \\ Department of Clinical Biochemistry, Medical School, University of Otago, Dunedin, New Zealand
}

\section{(Received 12 September 1979)}

\begin{abstract}
Rats from an inbred strain (NZR/Mh) were found to have high concentrations of glycogen in their livers, even after $24 \mathrm{~h}$ of starvation. Despite this, blood glucose concentrations were well maintained on starvation for up to $72 \mathrm{~h}$. The primary defect is a deficiency of liver phosphorylase kinase, causing a lack of active glycogen phosphorylase, although total phosphorylase is normal. The intravenous injection of glucagon caused a rapid activation of cyclic AMP-dependent protein kinase in the liver, but no increase in either phosphorylase kinase or phosphorylase $a$ activity. Although total glycogen synthase activity in the livers of affected rats was higher than normal, glycogen synthase in the active form was very low, presumably as a result of the high liver glycogen content. The condition is transmitted as autosomal recessive and, apart from hepatomegaly, the affected rats appear healthy.
\end{abstract}

In the course of liver-perfusion experiments with starved rats, two of us (D. G. C. and C. W.) noted very high glycogen content in the livers of some animals. We found that this occurred only in rats of an inbred strain (NZR/Mh) maintained in this Department; high glycogen concentrations during starvation were never observed in rats supplied by the University Animal Breeding Station. Using open liver glycogen content. In the present paper, we NZR/Mh strain of rats were affected. It turned out to be a simple matter to breed a line of rats with high liver glycogen content. In the present paper, we describe some features of the strain, and present evidence that the accumulation of glycogen is caused by a deficiency of liver phosphorylase kinase activity. A preliminary report on these rats has appeared (Malthus \& Clark, 1977).

\section{Materials and Methods}

The NZR/Mh strain of rats was derived from the NZR/Gd strain (Goodall et al., 1975) and had been maintained as a separate inbred strain for three generations when the glycogen-storage disease was discovered. We propose to designate the mutation responsible for the excessive glycogen deposition gsd (glycogen-storage disease); affected rats homozygous for the disorder will thus be designated gsd/gsd and heterozygotes $g s d /+$. Three sublines of

* Present address: Division of Human Nutrition, C.S.I.R.O., Kintore Avenue, Adelaide, South Australia 5000, Australia. the NZR/Mh strain are currently maintained in our Department. Two sublines were started by brother/ sister mating of affected ( $g s d / g s d$ ) rats; these are homozygous for the gsd mutation and all have high liver glycogen contents in starvation. Another subline was started by mating obligate heterozygotes $(\mathrm{gsd} /+)$ with affected ( $\mathrm{gsd} / \mathrm{gsd}$ ) animals and has been maintained by brother/sister mating of gsd/gsd with $g s d /+$ animals. Thus each litter has approx. $50 \%$ of affected (gsd/gsd) rats; the others are obligate heterozygotes $(\mathrm{gsd} /+)$ and have normal liver glycogen concentrations on starvation. In this subline, affected rats are identified by analysis of glycogen in samples of liver obtained by open biopsy from rats starved for $24 \mathrm{~h}$. For comparison we have also used rats from the random-bred closed colony at the University Animal Breeding Station, these being referred to as ABS rats. The animals were housed in metal cages, on wood shavings, in a conventional animal room, with temperature controlled between $19^{\circ} \mathrm{C}$ and $25^{\circ} \mathrm{C}$. Tap water and a pelleted diet (Otago Breeder) were available ad libitum. The diet contained (by wt.) $22 \%$ crude protein, $5 \%$ fat, $4.5 \%$ fibre, $2.5 \%$ ash, $6 \%$ moisture and $60 \%$ total carbohydrate by difference. ABS rats were kept for at least 1 week under these conditions before being used in experiments. When rats were starved, bedding material was replaced to prevent food carry-over, and drinking water was available ad libitum.

Liver biopsies were carried out by laparotomy under ether anaesthesia, by using a ligature to 
control bleeding. In the early stages of the investigation it was necessary to biopsy every rat of the NZR/Mh strain, but we now biopsy routinely only the offspring of $g s d / g s d \times g s d /+$ matings, usually at 7-8 weeks of age. In the experiments described here, rats from 2 to 3 months old were usually used, although affected animals have been kept up to the age of 2 years. For enzyme assays, liver samples were obtained under pentobarbital anaesthesia $(60 \mathrm{mg} / \mathrm{kg}$, intraperitoneally; Nembutal; Abbott Laboratories, Naenae, New Zealand). When consecutive samples were taken, a lobe was tied off immediately after sampling. The liver samples were usually homogenized immediately in the appropriate buffer, because, in our experience, losses of phosphorylase kinase occurred when samples were freeze-clamped. Additional liver samples were always taken for glycogen assay.

\section{Glycogen and blood glucose}

Tissue samples for glycogen assay were weighed in tubes containing $3 \mathrm{ml}$ of $30 \%(\mathrm{w} / \mathrm{v}) \mathrm{KOH}$, saturated with $\mathrm{Na}_{2} \mathrm{SO}_{4}$. They were digested in a boiling-water bath and the glycogen was isolated as described by Lo et al. (1970). The glycogen was redissolved in $5 \mathrm{ml}$ of water and was assayed either by the phenol $/ \mathrm{H}_{2} \mathrm{SO}_{4}$ method (Lo et al., 1970) or by an enzymic method, in which glycogen was digested with amyloglucosidase as described by Hue et al. (1975), and the resulting glucose solution was assayed with a commercial kit (GOD-Perid; Boehringer Mannheim G.m.b.H., Mannheim, W. Germany). Samples of liver, skeletal muscle (biceps femoris), kidney and heart gave essentially the same results by either method, but with lung and brain samples the chemical method gave markedly higher results than the enzymic method; for these latter tissues we have therefore reported only results obtained by the enzymic method.

Blood was withdrawn from the jugular vein under pentobarbital anaesthesia and immediately deproteinized with $0.16 \%$ uranyl acetate in $0.9 \% \mathrm{NaCl}$. Glucose in the supernatant was assayed as for the glycogen assay.

\section{Enzyme assays}

All solutions and all steps before the actual incubations were at $0-4^{\circ} \mathrm{C}$. When the $\mathrm{pH}$ of buffers was adjusted at $0^{\circ} \mathrm{C}$, both the glass electrode and the reference electrode were at this temperature. For phosphorylase and phosphorylase kinase assays, fresh liver samples were quickly weighed in $10 \mathrm{vol}$. of homogenizing buffer, consisting of $50 \mathrm{~mm}$-Tris, $50 \mathrm{~mm}$-NaF, $5 \mathrm{~mm}$-EDTA and $30 \mathrm{~mm}-\beta$-mercaptoethanol adjusted to $\mathrm{pH} 8.2$ at $0^{\circ} \mathrm{C}$ with $1 \mathrm{M}-\mathrm{HCl}$, and immediately homogenized (Polytron, step 3, 10s; Kinematica G.m.b.H., Lucerne, Switzerland). Homogenates were centrifuged at $1500 \mathrm{~g}$ for $1 \mathrm{~min}$, and the supernatants used in the assays. For phosphorylase $a$ determination, a portion of the supernatant was diluted 10 -fold in a diluting buffer comprising $50 \mathrm{~mm}$-Mes (4-morpholine-ethanesulphonic acid), $30 \mathrm{~mm}-\mathrm{NaF}, 2 \mathrm{~mm}-\mathrm{EDTA}$ and $30 \mathrm{~mm}-$ $\beta$-mercaptoethanol adjusted to $\mathrm{pH} 6.3$ at $0^{\circ} \mathrm{C}$ with $5 \mathrm{M}-\mathrm{KOH}$. Phosphorylase $a$ was assayed at $30^{\circ} \mathrm{C}$ in the direction of glycogen synthesis by the method of Tan \& Nuttall (1975) except that AMP was omitted and caffeine included at a final concentration of $1.7 \mathrm{~mm}$ to suppress phosphorylase $b$ activity. Total phosphorylase activity was measured after activation with rabbit muscle phosphorylase kinase. To $100 \mu \mathrm{l}$ of homogenate supernatant were added $50 \mu \mathrm{l}$ of phosphorylase kinase $(15 \mathrm{units} / \mathrm{ml})$ and $50 \mu \mathrm{l}$ of $\mathrm{ATP} / \mathrm{Mg}$ solution (see below) to give a final concentration of $12 \mathrm{mM}-\mathrm{ATP}$ and $10 \mathrm{~mm}-\mathrm{mag}$ nesium acetate. After incubation at $30^{\circ} \mathrm{C}$ for $30 \mathrm{~min}$, the reaction mixture was diluted 10 -fold with cold diluting buffer, and the phosphorylase $a$ assayed as described above. One unit of phosphorylase $a$ activity catalysed the incorporation into glycogen of $1 \mu \mathrm{mol}$ of glucose/min. For phosphorylase kinase assay $100 \mu \mathrm{l}$ of the homogenate supernatant was mixed with $50 \mu$ l of muscle phosphorylase $b(20 \mathrm{mg} /$ $\mathrm{ml}$ in homogenizing buffer). After the addition of $50 \mu \mathrm{l}$ of ATP/Mg solution ( $50 \mathrm{mM}-\mathrm{ATP} / 40 \mathrm{mM}-\mathrm{mag}$ nesium acetate in $10 \mathrm{~mm}$ - Tris $/ \mathrm{HCl}, \mathrm{pH} 7.8$ ) a zerotime sample was withdrawn and diluted 10 -fold in diluting buffer. The remaining mixture was incubated for $10 \mathrm{~min}$ at $30^{\circ} \mathrm{C}$ and the reaction stopped by 10 -fold dilution in cold diluting buffer, followed by assay of phosphorylase $a$ as above. One unit of phosphorylase kinase catalysed the formation of 1 unit of phosphorylase $a / \mathrm{min}$.

Cyclic AMP-dependent protein kinase was assayed as described by Cherrington et al. (1976). One unit catalysed the incorporation into histone of $1 \mu \mathrm{mol}$ of $\mathrm{P}_{1} / \mathrm{min}$. For glycogen synthase assays, samples of liver were freeze-clamped at the temperature of liquid $\mathrm{N}_{2}$ before being assayed as described by Watts \& Gain (1976). Total glycogen synthase activity was measured at $30^{\circ} \mathrm{C}$ in the presence of $7 \mathrm{mM}$-glucose 6-phosphate and active glycogen synthase in the presence of $15 \mathrm{mM}-\mathrm{Na}_{2} \mathrm{SO}_{4}$. One unit of glycogen synthase activity catalysed the incorporation into glycogen of $1 \mu \mathrm{mol}$ of glucose from UDP-glucose/min.

Glucose 6-phosphatase (Baginski et al., 1974), debranching enzyme (Nelson \& Larner, 1970) and phosphofructokinase (Tsai \& Kemp, 1974) were also assayed in a small number of liver samples.

\section{Chemicals}

Rabbit muscle phosphorylase $b$, histone II-A, oyster glycogen (type 2), $\alpha$-D-glucose 1-phosphate (dipotassium salt, grade 1), UDP-glucose and amyloglucosidase (grade 2; EC 3.2.1.3) were 
purchased from Sigma Chemical Co. (St. Louis, MO, U.S.A.); [U-1 $\left.{ }^{14} \mathrm{C}\right]$ glucose 1-phosphate, UDP$\left[\mathrm{U}-{ }^{14} \mathrm{C}\right.$ ]glucose and $\left[{ }^{32} \mathrm{P}\right]$ phosphate were from The Radiochemical Centre (Amersham, Bucks., U.K.) and glucagon was from Eli Lilly and Co. (Indianapolis, IN, U.S.A.). Glycogen was further purified by two treatments with $15 \%(\mathrm{w} / \mathrm{v})$ trichloroacetic acid and five precipitations from $66 \%(\mathrm{v} / \mathrm{v})$ ethanol, the final precipitate being dried in vacuo at $4^{\circ} \mathrm{C}$. Rabbit muscle phosphorylase kinase was isolated by the method of Cohen (1973), except that Sepharose CL6B was used in place of Sepharose 4B in the final step. The active fractions, which were free from glycogen phosphorylase activity, were stored in small batches at $-20^{\circ} \mathrm{C}$. $\left[\gamma^{-32} \mathrm{P}\right]$ ATP was prepared by the method of Glynn \& Chappell (1964), as modified by Walsh et al. (1971).

\section{Results}

In Table 1 we have summarized results for the liver glycogen content in the rats that we have so far studied. These include affected ( $g s d / g s d)$, heterozygotes $(\mathrm{gsd} /+)$ and random-bred ABS rats. Even in the fed state, average liver glycogen concentrations in affected rats were considerably higher than those in either control group (ABS rats or heterozygotes). Whereas starvation for $24 \mathrm{~h}$ caused virtually complete loss of glycogen from the livers of control rats, affected rats lost none of their liver glycogen, although there was a loss of about $15 \%$ during the second $24 \mathrm{~h}$ of starvation. However, this rate of loss was not maintained, for the liver glycogen concentrations in nine rats starved for $72 \mathrm{~h}$ was $612 \pm 29 \mu \mathrm{mol}$ of glucose units/g wet wt. (mean \pm S.E.M.). When two affected ( $g s d / g s d)$ and two ABS rats were starved for 9 days, liver glycogen concentrations were 414 and $526 \mu \mathrm{mol} / \mathrm{g}$ wet wt. in the affected rats, but were undetectable in controls.

In histological sections from livers of starved gsd/gsd rats the high glycogen content was readily demonstrated, in contrast with the virtual absence of glycogen in sections from control livers. In electron micrographs prepared from the liver of $g s d / g s d$ rats, the glycogen is more or less evenly distributed throughout the cytoplasm (Plate 1); no evidence was seen of association of glycogen with any organelle.

Glycogen concentrations in other tissues of rats starved for $24 \mathrm{~h}$ are presented in Table 2; the liver glycogen content is also shown for comparison. Whereas skeletal-muscle glycogen contents were the same in the two groups, there were significant

\section{Table 1. Liver glycogen content in fed and starved rats}

Glycogen content is expressed as $\mu \mathrm{mol}$ of glucose equivalent/g wet wt. of liver for rats aged 3-6 months. Values are means \pm S.E.M. for the numbers of rats shown in parentheses. ABS rats are random-bred rats from the University Animal Breeding Station.

$\begin{array}{llccc}\text { Fed } & \overbrace{\text { Starved }}^{\text {Siver glycogen }} \\ \text { Affected }(g s d / g s d) \text { rats } & 697 \pm 15.8(78) & 696 \pm 11.2(255) & 588 \pm 15.0(56) \\ \text { Heterozygotes }(g s d /+) & 254 \pm 10.6(92) & 12.1 \pm 0.8 & (187) & - \\ \text { ABS rats } & 317 \pm 10.2(97) & 8.5 \pm 1.1 & (57) & -\end{array}$

Table 2. Glycogen in other tissues compared with liver

Rats were starved for $24 \mathrm{~h}$; the glycogen was isolated and assayed as described in the Materials and Methods section. Results are expressed as $\mu \mathrm{mol}$ of glucose equivalent/g wet wt. Values are means \pm S.E.M. for the numbers of samples in parentheses. The control group includes both $\mathrm{gsd} /+$ and ABS rats, which had similar amounts of tissue glycogen. $P$ was calculated by Student's $t$ test.

\begin{tabular}{|c|c|c|}
\hline & \multicolumn{2}{|c|}{ Tissue glycogen } \\
\hline & Controls & Affected rats (gsd/gsd) \\
\hline Skeletal muscle & $23.4 \pm 0.88(37)$ & $23.3 \pm 0.81(36)$ \\
\hline Heart & $16.6 \pm 1.33(39)$ & $22.3 \pm 1.68(37)(P<0.01)$ \\
\hline Kidney & $4.43 \pm 0.43(39)$ & $8.90 \pm 0.33(37)(P<0.001)$ \\
\hline Lung & $3.28 \pm 0.32(16)$ & $13.3 \pm 1.21(17)(P<0.001)$ \\
\hline Brain & $1.32 \pm 0.28(16)$ & $1.76 \pm 0.26(16)(P>0.2)$ \\
\hline Liver & $7.22 \pm 1.32(39)$ & $661 \pm 17.8(38)$ \\
\hline
\end{tabular}


Table 3. Liver glycogen in foetal and newborn rats Results are expressed as $\mu \mathrm{mol}$ of glucose equivalent $/ \mathrm{g}$ wet $w t$; values are means \pm s.E.M. The numbers in parentheses refer to the numbers of litters examined for normal rats and the numbers of rats examined for affected rats. Values for normal rats are taken from results obtained earlier in this Department (Watts \& Gain, 1976).

\begin{tabular}{lcc}
\multicolumn{1}{c}{ Age } & $\overbrace{\text { Normal rats }}$ Liver glycogen & Affected rats \\
Pre-natal, full-term & $378 \pm 23(10)$ & $450 \pm 17.7(18)$ \\
$24 \mathrm{~h}$ & $83 \pm 8(14)$ & $521 \pm 30.9(19)$ \\
3 days & - & $632 \pm 38.6(11)$
\end{tabular}

Table 4. Inheritance of high liver glycogen content Male rats with high liver glycogen contents on starvation were mated with (normal) female ABS rats (first mating). the progeny are designated $F_{1}$. Female $F_{1}$ rats were then either back-crossed to their male (affected) parent or mated to male littermates $\left(F_{1} \times F_{1}\right)$. Ten matings of each type were made, and liver glycogen contents were assayed in all offspring after $24 \mathrm{~h}$ without food. The results are expressed as the fraction of the offspring with high liver glycogen.

\begin{tabular}{|c|c|c|c|}
\hline \multirow[b]{2}{*}{ Mating } & \multirow[b]{2}{*}{ Result } & \multicolumn{2}{|c|}{ Expected } \\
\hline & & Recessive & Dominant \\
\hline $\begin{array}{l}\text { First } \\
\text { Back-cross }\end{array}$ & $\begin{array}{c}0 / 119 \\
48 / 103(47 \%)\end{array}$ & $\begin{array}{c}0 \\
50 \%\end{array}$ & $\begin{array}{c}50 \% \text { or } 100 \% \\
-\end{array}$ \\
\hline & & Autosomal & $\mathrm{X}$-linked \\
\hline$F_{1} \times F_{1}$ & $\begin{array}{c}18 / 101(18 \%)^{*} \\
\left(8 \sigma^{\top}, 10 \%\right)\end{array}$ & $\begin{array}{c}25 \% \\
\text { equal } \delta^{x}+q\end{array}$ & $\begin{array}{l}25 \% \\
\text { all } \sigma^{7}\end{array}$ \\
\hline
\end{tabular}

* The observed value of $18 \%$ does not differ significantly from the expected value of $25 \%(P>0.1$, calculated from the binomial distribution). differences in heart, kidney and lung glycogen, with the $g s d / g s d$ rats having higher values in each case.

Table 3 shows that higher than normal amounts of glycogen were already present in foetal livers at full term. Normal rats showed a marked fall in the concentration of glycogen in the liver during the first $24 \mathrm{~h}$ of extra-uterine life, whereas the $\mathrm{gsd} / \mathrm{gsd}$ rats maintained or possibly increased their liver glycogen content over this period. The livers of 3-day-old $g s d / g s d$ rats already had virtually as much glycogen as adult rats. Only a few measurements have been made in rats older than 4 months, but there appeared to be a gradual decline in liver glycogen concentrations beyond the age of 6 months, and in nine affected rats, average age 20 months, starved for $24 \mathrm{~h}$, the liver glycogen concentration was $220 \pm 28 \mu \mathrm{mol} / \mathrm{g}$ wet wt. (mean \pm S.E.M.).

Hepatomegaly was a constant feature in the affected rats and was obvious at laparotomy. For example, in 32 male $g s d / g s d$ rats weighing between $150 \mathrm{~g}$ and $350 \mathrm{~g}$ the liver-weight/body-weight ratio was $4.30 \pm 0.085 \mathrm{~g} / 100 \mathrm{~g}$, versus $2.72 \pm 0.058 \mathrm{~g} /$ $100 \mathrm{~g}$ (mean \pm S.E.M.) for 26 control rats in the same weight range.

In order to study the genetics of the condition, test matings were made by using affected $(g s d / g s d)$ male rats and female ABS rats, which were presumed to be free of the genetic defect. The data in Table 4 show that the condition is transmitted as Mendelian autosomal recessive. As would be expected, when two affected $(g s d / g s d)$ rats are mated all the progeny have high liver glycogen content.

The rats are remarkably little affected by the disorder and outwardly appear quite healthy. They breed well, the litter size is normal and there is no excessive mortality in the neonatal period. The only apparent abnormality is enlargement of the liver, but this is observable only at laparotomy. We have been

Table 5. Blood glucose concentrations in rats with glycogen-storage disease

Blood samples were withdrawn from the jugular vein under pentobarbital anaesthesia, and glucose was measured as described in the Materials and Methods section. Values are expressed as mmol of glucose/litre of whole blood, and are means \pm S.E.M.; numbers of rats in each group are in parentheses.

\begin{tabular}{|c|c|c|c|}
\hline & \multicolumn{3}{|c|}{ Blood glucose } \\
\hline & \multirow[t]{2}{*}{ ABS rats } & \multicolumn{2}{|c|}{$\mathrm{NZR} / \mathrm{Mh}$ rats } \\
\hline & & $\begin{array}{l}\text { Heterozygotes } \\
\quad(\text { gsd } /+)\end{array}$ & $\begin{array}{l}\text { Homozygotes } \\
\quad(g s d / g s d)\end{array}$ \\
\hline $\begin{array}{l}\text { Fed } \\
\text { Starved: }\end{array}$ & $5.71 \pm 0.17(30)$ & $5.34 \pm 0.17(14)$ & $4.65 \pm 0.18(20)$ \\
\hline $24 \mathrm{~h}$ & $3.49 \pm 0.09$ & $3.79 \pm 0.13(13)$ & $3.83 \pm 0.15(26)$ \\
\hline $48 \mathrm{~h}$ & $3.24 \pm 0.11(18)$ & $3.95 \pm 0.14(13)$ & $3.65 \pm 0.16(16)$ \\
\hline $72 \mathrm{~h}$ & $3.87 \pm 0.15(8)$ & - & $3.98 \pm 0.21(8)$ \\
\hline
\end{tabular}



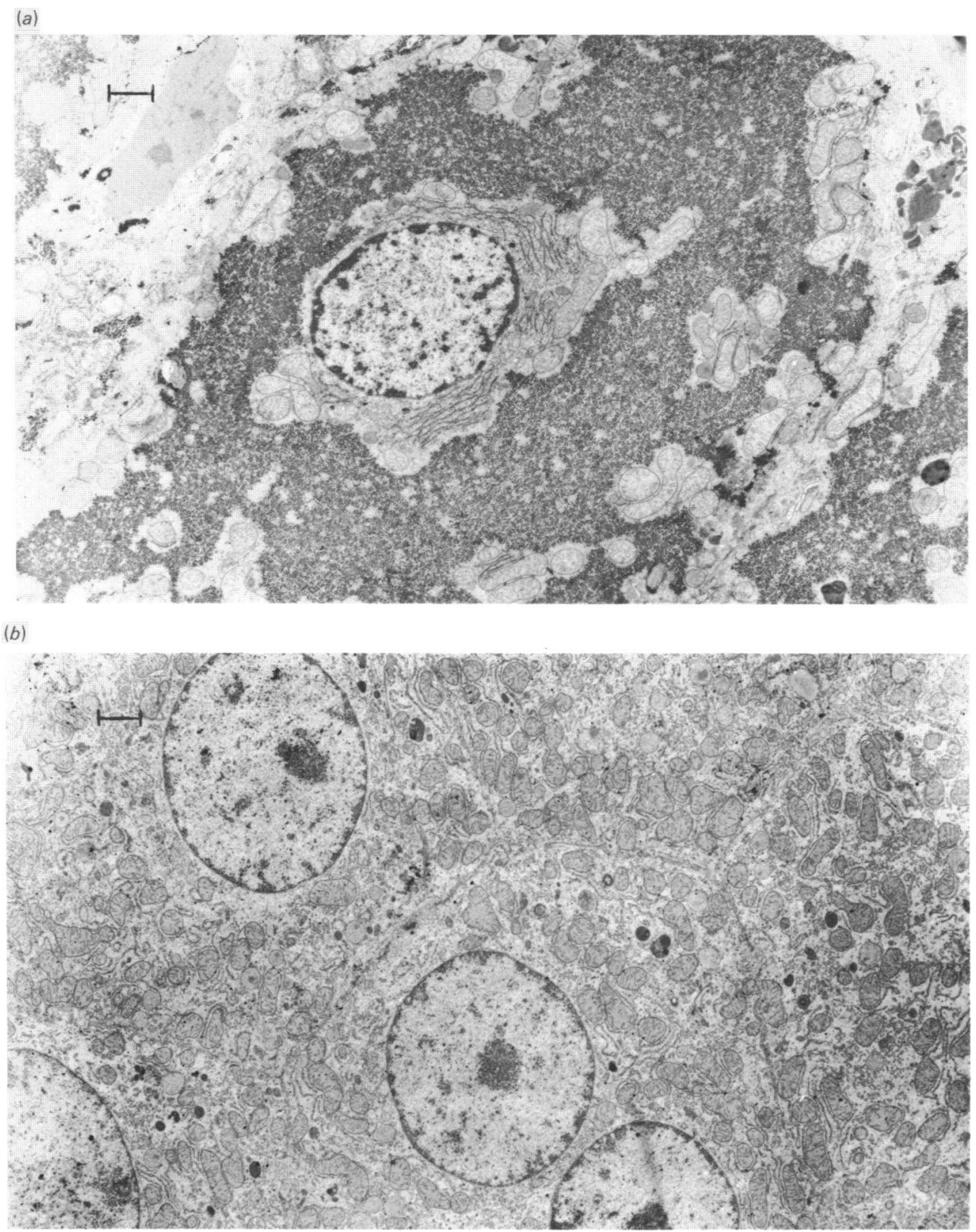

EXPLANATION OF PLATE 1

Electron micrographs of liver specimens from $24 \mathrm{~h}$-starved rats, showing (a) large depots of glycogen in cells of the gsd/gsd rat or (b) virtual absence of glycogen in cells of the control rat.

The bars represent $1 \mu \mathrm{m}$. 
unable to detect the condition by any method other than open liver biopsy. (Rats tolerate this operation remarkably well: operative losses have been approx. $3 \%$, almost entirely because of accidental asphyxia, and post-operative losses have been less than $1 \%$.)

\section{Blood glucose}

Affected $(g s d / g s d)$ rats had somewhat lower blood glucose concentrations in the fed state. However, after starvation for periods of 24-72h there was no clear difference between blood glucose concentrations in affected rats, ABS rats or heterozygotes (Table 5).

\section{Activities of liver enzymes}

A defect in any one of a number of enzymes could lead to excessive glycogen storage in the liver. We considered that a lysosomal glucosidase deficiency was unlikely, because there was no evidence of accumulation of glycogen in the lysosomes. We found normal activities of glucose 6-phosphatase, debranching enzyme and phosphofructokinase in the livers of affected rats, although only small numbers of rats were examined (Table 6). A clear-cut abnormality was detected in the phosphorylase system. Active phosphorylase in liver samples from affected rats was much lower than in control animals, whereas total phosphorylase activity was similar in both groups.

Phosphorylase kinase activity in the affected rats was very low, averaging only $6 \%$ of the activity found in normal rats. The cyclic AMP-dependent protein kinase activity and the activity ratio (-cyclic AMP/+cyclic AMP) were the same in both groups (Table 6).

The total glycogen synthase activity of starved gsd/gsd rats was higher than that of starved controls. There was a striking difference between the two groups in the amount of glycogen synthase present in the active form; $g s d / g s d$ rats had less than $1 \%$ in the active form, compared with over $10 \%$ in controls (Table 7). A group of normal (ABS) rats fed ad libitum had glycogen concentrations and glycogen synthase activities intermediate between those of the starved groups. Among affected rats, fed animals were indistinguishable from starved in terms of both glycogen content and glycogen synthase activity, and the results for the two groups have been combined in Table 7.

\section{Effect of glucagon injection on liver enzymes}

The injection of glucagon $(50 \mu \mathrm{g} / \mathrm{kg}$ body wt. intravenously) into normal rats doubled phosphorylase $a$ activity and increased phosphorylase

Table 6. Liver enzymes in rats with glycogen-storage disease

Values are means \pm S.E.M., with the numbers of rats examined in parentheses.

\begin{tabular}{lcc} 
& \multicolumn{2}{c}{ Ectivity (units/g wet wt.) } \\
\cline { 2 - 3 } Elucymes & $\begin{array}{c}\text { Normal rats (ABS) } \\
\text { Affected rats }(g s d / g s d)\end{array}$ \\
Debranching enzyme & $8.9 \pm 0.35(13)$ & $8.3 \pm 0.49(8)$ \\
Phosphofructokinase & $3.8 \pm 0.35(4)$ & $3.3 \pm 0.87(3)$ \\
Active phosphorylase & $0.86 \pm 0.15(3)$ & $0.93 \pm 0.13(3)$ \\
Total phosphorylase & $5.23 \pm 0.72(18)$ & $0.43 \pm 0.11(19)$ \\
Phosphorylase kinase & $16.2 \pm 1.3(16)$ & $17.3 \pm 1.5(15)$ \\
Protein kinase: & $6.3 \pm 0.3(10)$ & $0.4 \pm 0.11(10)$ \\
- cyclic AMP & $15.1 \pm 1.2(6)$ & $15.9 \pm 1.5(6)$ \\
+ cyclic AMP & $30.9 \pm 1.7(6)$ & $30.4 \pm 2.2(6)$
\end{tabular}

Table 7. Liver glycogen synthase in normal rats and rats with glycogen-storage disease Activities are expressed in units/g wet wt. Values are means \pm S.E.M., with the numbers of animals in parentheses. Values for $24 \mathrm{~h}$-starved and fed $g s d / g s d$ rats were almost identical and have been combined. ${ }^{* *} P<0.001,{ }^{*} P<0.025$, compared with starved normals (Student's $t$ test).

Affected (gsd/gsd) starved and fed (19)

Normal (ABS), starved (15)

Normal (ABS), fed (10)
Liver glycogen ( $\mu \mathrm{mol} / \mathrm{g}$ wet wt.) $648 \pm 13$ $2.7 \pm 0.6$ $329 \pm 22$
Glycogen synthase

\begin{tabular}{llc} 
Total & \multicolumn{1}{c}{ Active } & \% active \\
$3.38 \pm 0.14^{* *}$ & $0.03 \pm 0.002^{* *}$ & $0.9 \pm 0.1^{* *}$ \\
$2.25 \pm 0.1$ & $0.26 \pm 0.02$ & $11.6 \pm 0.9$ \\
$2.54 \pm 0.07^{*}$ & $0.14 \pm 0.02^{* *}$ & $5.5 \pm 0.8^{* *}$
\end{tabular}


Table 8. Effect of glucagon on liver enzymes

Enzyme activities were measured in anaesthetized rats before and $5 \mathrm{~min}$ after the intravenous injection of glucagon $(50 \mu \mathrm{g} / \mathrm{kg})$ and are expressed in units $/ \mathrm{g}$ wet wt. of liver. Values are means \pm S.E.M. for five rats in each group.

$\begin{array}{ccc} & \begin{array}{c}\text { Enzyme activity (units/g wet wt.) } \\$\cline { 2 - 2 } $\begin{array}{c}\text { Normal rats } \\ \text { (ABS) }\end{array}\end{array} & \begin{array}{c}\text { Affected rats } \\ (\mathrm{gsd} / \mathrm{gs} d)\end{array} \\ \begin{array}{c}\text { Phosphorylase } a \\ \text { Before glucagon }\end{array} & \begin{array}{c}5.0 \pm 1.1 \\ \text { After glucagon }\end{array} & 0.4 \pm 0.24 \\ \text { Total phosphorylase } & 10.6 \pm 0.38 & 0.8 \pm 0.46 \\ \text { Before glucagon } & 12.3 \pm 2.4 & 13.8 \pm 1.8 \\ \text { After glucagon } & 13.3 \pm 2.3 & 14.5 \pm 2.4 \\ \text { Phosphorylase kinase } & & \\ \text { Before glucagon } & 5.3 \pm 0.77 & 0.5 \pm 0.39 \\ \text { After glucagon } & 7.7 \pm 0.83 & 0.6 \pm 0.45 \\ \text { Protein kinase activity ratio } \\ \text { Before glucagon }\end{array}$

kinase activity by about $45 \%$, but had no effect on total phosphorylase activity (Table 8). In $g s d / g s d$ rats, glucagon injection had no significant effect on any of the three enzymes. Glucagon caused a rapid activation of cyclic AMP-dependent protein kinase in the livers of both groups of rats, with the activity ratio approaching 1.0 (Table 8). This is good evidence that glucagon raises the cyclic AMP concentrations normally in the affected rats.

We have been unable to detect any biochemical abnormalities in the heterozygotes. Rats that are obligate heterozygotes for the abnormal gene ( $g s d /+$ ) do not have abnormally high liver glycogen in either fed or starved states (Table 1), nor are their phosphorylase or phosphorylase kinase activities different from those in ABS rats.

\section{Discussion}

Glycogen-storage diseases have been studied much more in man than in domestic or laboratory animals. To the best of our knowledge, this is the first report of a liver glycogen-storage disorder in a laboratory species, though phosphorylase kinase deficiency in muscle in the I-strain mouse is well described (see, e.g., Lyon, 1970). Huijing (1975) lists enzyme defects involving glycogen metabolism in dogs, cats and sheep, and lysosomal glucosidase deficiency has been reported in cattle (see, e.g., Jolly et al., 1977).

The NZR/Mh strain of gsd rats is derived from the NZR/Gd strain of albino rat and had been maintained separately for only three generations when the glycogen-storage disorder was discovered; it is currently in the F-12 generation. We have been unable to obtain sufficient animals from the NZR/Gd strain to learn if these rats also carry the genetic defect. The NZR/Gd strain is derived, in turn, from the AS2 strain (Heslop, 1968), but we have not found excess liver glycogen in any AS2 rats examined, nor did matings between AS2 rats and gsd/gsd animals from the NZR/Mh strain produce any affected offspring. The AS2 strain itself originated, by selection and inbreeding, from the ABS colony, which has remained a closed colony to this day. Despite the accumulation of large amounts of glycogen in the liver, the animals are remarkably little affected by the condition; there is no obvious shortening of the life-span, nor any increase in neonatal mortality. Despite the very low activities of phosphorylase kinase and phosphorylase $a$ and presumably very low rates of glycogen breakdown via the phosphorylase system, there is no hypoglycaemia on starvation. Presumably glucose is produced either by gluconeogenesis or by glycogen breakdown by pathways not involving phosphorylase. On the basis of the evidence presented, we think that the condition in the affected rats is caused by a deficiency of liver phosphorylase kinase activity. We believed that the assay we used for phosphorylase kinase activity measured total phosphorylase kinase activity in liver homogenates, because incubation of homogenates with $\mathrm{ATP} / \mathrm{Mg}$ and cyclic AMP as described by Vandenheede et al. (1977) failed to increase the activity of the enzyme. It is thus rather surprising that injection of glucagon into normal rats increased liver phosphorylase kinase activity by $45 \%$.

Because the assay of liver phosphorylase kinase depends on activation of the enzyme by endogenous 
factors, the decreased phosphorylase kinase activity observed in affected rats could be caused by a deficiency of phosphorylase kinase itself or by a defect in the activation system. The phosphorylase kinase-activation system in affected rats appears to be normal in that the cyclic AMP-dependent protein kinase activity and the activity ratio (-cyclic AMP/+cyclic AMP) are the same as in normal rats (Table 7). The injection of glucagon into $\mathrm{gsd} / \mathrm{gsd}$ rats produced complete activation of the protein kinase, but failed to cause any increase in phosphorylase kinase activity. Finally, no increase in phosphorylase kinase activity in homogenates of liver from affected rats could be observed after manipulations reported to activate phosphorylase kinase in homogenates of liver from normal rats, i.e. incubation of homogenates with exogenous cyclic AMP-dependent protein kinase or with added $\mathrm{CaCl}_{2}$ $(1 \mu \mathrm{M}-1 \mathrm{mM})$.

Affected rats appear to have some small activity, but it is not clear whether this represents phosphorylase kinase activity or whether it reflects the imprecision of the assay. The measured phosphorylase kinase activity in affected rats varied from zero to as much as 1.2 units/g wet wt., i.e. about $20 \%$ of the activity in normal rats. In some cases there seemed to be an increase in phosphorylase kinase activity in response to glucagon, but there was little correlation between phosphorylase kinase and phosphorylase $a$ activities measured in the same samples $(r=0.40,15$ rats). Thus we cannot at present decide whether phosphorylase kinase activity is very low or absent.

An alternative explanation of the enzyme results would be the presence in the livers of $g s d / g s d$ rats of an inhibitor of phosphorylase kinase. However, in a mixture of equal volumes of liver homogenates from an affected and a normal rat, the phosphorylase kinase activity was equal to half that in the normal homogenate.

The presence of increased amounts of glycogen in heart, kidney and lung is intriguing. We do not know whether this results from the primary disorder of the liver or whether these tissues also have decreased amounts of phosphorylase kinase. Our failure to detect decreased liver phosphorylase kinase activity in obligate heterozygotes may be due to the type of assay used. On the other hand, by analogy with the muscle enzyme, liver phosphorylase kinase probably consists of more than one type of subunit. If the rate of synthesis of only one subunit were halved, it is conceivable that this would not affect the rate of assembly of the holoenzyme.

The differences in glycogen synthase activity are presumably secondary to the accumulation of glycogen in the liver. There is no direct evidence to indicate the mechanism responsible for the inactivation of the enzyme, although the degree of activa- tion of glycogen synthase in fed and starved normal rats and in the affected rats correlated inversely with the amount of glycogen present ( $r=0.88,44$ rats). It may be significant that glycogen has been shown to inhibit the conversion of inactive glycogen synthase into the active form (De Wulf \& Hers, 1968). Affected rats had higher total glycogen synthase activity than the controls. Total glycogen synthase in the three groups of animals in Table 7 correlates well with the glycogen content of the liver $(r=0.71$, 44 rats), but it is not clear how an increase in glycogen storage would lead to an increase in total glycogen synthase activity. Further studies on these rats are needed to elucidate these problems.

We believe that this strain of rats will be a useful model of the rare deficiency of liver phosphorylase kinase in man. They should also be valuable for the study of glycogen synthesis and degradation, and the control of blood glucose concentrations.

This work was supported by grants from the Medical Research Council of New Zealand. We thank Mr. C. F. O'Malley, Mr. John Ten Have, Miss Sharon Geddes and Miss Julie Ockwell for technical assistance; histological sections for light microscopy were prepared in the Pathology Department and the electron micrographs were prepared by Christine Nickolai, at the E.M. Facility, Flinders University, Adelaide, Australia.

\section{References}

Baginski, E. S., Foa, P. P. \& Zak, B. (1974) in Methods of Enzymatic Analysis (Bergmeyer, H. U., ed.), 3rd edn., vol. 1, pp. 876-880, Academic Press, New York

Cherrington, A. D., Assimacopoulos, F. D., Harper, S. C., Corbin, J. D., Park, C. R. \& Exton, J. H. (1976) J. Biol. Chem. 251, 5209-5218

Cohen, P. (1973) Eur. J. Biochem. 34, 1-14

De Wulf, H. \& Hers, H. G. (1968) Eur. J. Biochem. 6, $552-557$

Glynn, I. M. \& Chappell, J. B. (1964) Biochem. J. 90, 147-149

Goodall, C. M., Christie, G. S. \& Hurley, J. V. (1975) J. Pathol. 116, 239-251

Heslop, B. F. (1968) Aust. J. Exp. Biol. Med. Sci. 46, 479-491

Hue, L., Bontemps, F. \& Hers, H. G. (1975) Biochem. J. 152, $105-114$

Huijing, F. (1975) Physiol. Rev. 55, 609-658

Jolly, R. D., Van-de-Water, N. S., Richards, R. B. \& Dorling, P. R. (1977) Aust. J. Exp. Biol. Med. Sci. 55, 141-150

Lo, S., Russell, J. C. \& Taylor, A. W. (1970) J. Appl. Physiol. 28, 234-236

Lyon, J. B., Jr. (1970) Biochem. Genet. 4, 169-185

Malthus, R. S. \& Clark, D. G. (1977) Proc. Univ. Otago Med. Sch. 55, 31-32

Nelson, T. E. \& Larner, J. (1970) Anal. Biochem. 33, 87-101

Tan, A. W. H. \& Nuttall, F. Q. (1975) Biochim. Biophys. Acta 410, 45-60

Vol. 188 
Tsai, M. Y. \& Kemp, R. G. (1974) J. Biol. Chem. 249, $6590-6596$

Vandenheede, J. R., Keppens, S. \& De Wulf, H. (1977) Biochim. Biophys. Acta 481, 463-470
Walsh, D. A., Perkins, J. P., Brostrom, C. O., Ho, E. S. \& Krebs, E. G. (1971) J. Biol. Chem. 246, 1968-1976

Watts, C. \& Gain, K. R. (1976) Biochem. J. 160, 263-270 